\title{
Investigation of nucleation and growth mechanism during electrochemical deposition of nickel on fluorine doped tin oxide substrate
}

\author{
Ali Mashreghi*, Hajar Zare
}

\begin{abstract}
Electrochemical deposition is an alternative method for metallization of semiconductors due to its low cost, simplicity and scalability. Knowing the mechanism of nucleation and growth during electrochemical deposition of metal films on semiconductor substrates is required for obtaining metallization with superior performance. In the present work, the mechanism of nucleation and growth during electrochemical deposition of Ni on fluorine doped tin oxide (FTO) substrate was investigated using a physical model which was proposed by Scharifker-Hills in 1983.

Voltammetric and chronoamperometric measurements were performed using three electrodes electrochemical cell. Scan rate dependence of anodic and cathodic peaks of voltammograms showed that the nucleation and growth are controlled by diffusion of $\mathrm{Ni}^{2+}$ ions to growing centers. Moreover, the measured current transient curves were compared to those calculated from Scharifker-Hills model for both instantaneous and progressive nucleation mechanisms. It was found that instantaneous nucleation mechanism governs the nucleation and growth of Ni on FTO substrate during electrochemical deposition.
\end{abstract}

Keywords: Electrochemical deposition; Chronoamperometry; Nickel; Fluorine doped tin oxide

${ }^{*}$ Corresponding author. Tel./Fax.: +98 7137354520 . E-mail addresses: mashreghi@sutech.ac.ir, alimashreghy@yahoo.com (A. Mashreghi) 


\section{Introduction}

Metallization of semiconductors is one of the important technological processes which is employed in different industries, such as microelectronic, optoelectronic, magnetooptic and photovoltaic industries. Metallization is usually employed for the fabrication of grid network of photovoltaic modules, Schottky barriers, diffusion barriers, ohmic contacts, interconnections and multilayer read/write heads. Metallization of semiconductors is usually carried out by physical vapor deposition techniques, such as molecular beam epitaxy and sputtering $[1,2]$. However, electrochemical deposition technique has received considerable attention as an alternative approach for deposition of metallic films on semiconductor surfaces, due to its lower cost, more scalability and more simplicity [3,4]. Electrochemical deposition of metals on semiconductor surfaces differs significantly from that of metals on metallic surfaces. Due to the weak interaction energy between adsorbed metal atoms and semiconductor surface, electrochemical deposition of metal films on semiconductor surfaces requires high overpotential and it follows a three dimensional (3D) island formation mechanism, also known as Volmer-Weber mechanism $[5,6]$. According to this mechanism, 3D nucleation takes place at possible active sites of substrate surface and then all nuclei grow three-dimensionally until they collide with each other to form a continuous metallic film [7]. Thus, for the formation of metallic film with superior characteristics it is required to understand the mechanism of nucleation and subsequent growth of nuclei at early stage of electrochemical deposition.

In $3 \mathrm{D}$ island film formation, the nucleation and the subsequent diffusion controlled growth can take place by two different mechanisms; instantaneous nucleation and progressive nucleation [5]. Instantaneous nucleation takes place when the rate of nucleation is faster than subsequent growth rate of nuclei. In this case, all nuclei are formed within very short time at 
early stage of electrochemical deposition. In progressive nucleation, the nucleation rate is comparable to the subsequent growth rate and the nucleation process will continue while priori formed nuclei are growing. A most successful physical model for the description of 3D nucleation with subsequent diffusion controlled growth is that proposed by Scharifker and Hills [8]. Current transient technique, also known as chronoamperometry, is a well-known electrochemical technique for determining the mechanism of nucleation and growth. In this technique, variation of current versus time is recorded under a constant applied working electrode potential. Then, mechanism of 3D nucleation and growth and some other information can be determined from the shape of the measured current transient curve, using a suitable physical model proposed by Scharifker and Hills. Using this method, the mechanism of nucleation and growth, under diffusion controlled mode, has been studied for the electrochemical deposition of different metals on different semiconductor substrates [5, 6, 9-14].

Metallized current collecting grid network is an essential part of 1st, 2nd and 3rd generation solar cells [15-17]. Dye sensitized solar cell (DSSC), as a third generation solar cell, is usually fabricated on fluorine-doped tin oxide (FTO) coated glass and thus, their current collecting grid network is metallized on the FTO surface, which is an n-type transparent semiconductor [18-21]. Requirements of DSSC metal grid network are its corrosion resistance against $\mathrm{I}^{-} / \mathrm{I}_{3}{ }^{-}$redox couple of electrolyte and its low dark current density to electrolyte. Recent investigations have shown that $\mathrm{Ni}$ is the most appropriate choice for current collecting metal grid of DSSC [19, 21]. Several techniques have been employed for deposition of Ni on FTO surface, such as physical vapor deposition and electrochemical deposition [19, 21-24]. Again, lower cost, more scalability and more simplicity are the advantages of electrochemical deposition of Ni on FTO. However, discontinuity and low adherence of coating are two important issues in 
electrochemical deposition of metals on semiconductors and investigations to address these issues are very scarce. In this respect, knowing and studying the mechanism of nucleation and subsequent growth at early stage of electrochemical deposition of Ni on FTO surface can be useful for subsequent investigations on improving continuity and adherence of Ni coating on FTO. However, to the knowledge of the authors, the mechanism of nucleation and subsequent growth at early stage of electrochemical deposition of Ni on FTO surface has not been studied yet.

In the present work, the mechanism of nucleation and growth at early stage of $\mathrm{Ni}$ electrodeposition on FTO surface was studied by cyclic voltammetry and chronoamperometry methods. The measured current transient curves were interpreted using the physical model of Scharifker and Hill.

\section{Experimental:}

FTO coated glass (solaronix) with $15 \Omega$ /square sheet resistance was used as substrate. Before electrochemical deposition, FTO surface was ultrasonically cleaned in acetone, isopropanol and ethanol, respectively. The Watt's bath was used for electrochemical deposition. The composition of bath was; $256 \mathrm{~g} / \mathrm{L} \mathrm{NiSO}_{4} \cdot 6 \mathrm{H}_{2} \mathrm{O}$ (Kimia-mavad Co., 99.0\%), $32 \mathrm{~g} / \mathrm{L} \mathrm{NiCl}_{2} \cdot 6 \mathrm{H}_{2} \mathrm{O}$ (Kimiamavad Co., 99.0\%) and $40 \mathrm{~g} / \mathrm{L} \mathrm{H}_{3} \mathrm{BO}_{3}$ (Kimia-mavad Co., 99.0\%) dissolved in deionized water. At this composition $\mathrm{pH}$ of bath was 3.9. Electrochemical deposition was performed at $45^{\circ} \mathrm{C}$. The effective area of FTO during electrochemical deposition was $0.5 \mathrm{~cm}^{2}$.

Electrochemical measurements were performed using three electrodes electrochemical cell. Reference electrode, working electrode and counter electrode were $\mathrm{Ag} / \mathrm{AgCl}, \mathrm{FTO}$ and $\mathrm{Ni}$, respectively. Potentiostat/galvanostat (Ivium, Verten) was used for voltammetric and chronoamperometric measurements. The voltammetric measurement was performed at three scan 
rates; 5,30 and $150 \mathrm{mV} / \mathrm{s}$. Current transient curve was measured by chronoamperometric technique. This measurement was carried out by stepping the potential from $-0.300 \mathrm{~V}$ vs $\mathrm{Ag} / \mathrm{AgCl}$ (as initialization step) to different potentials; $-0.750,-0.780,-0.800,-0.825,-0.850,-$ 0.880 and $-1.000 \mathrm{~V} v \mathrm{vs} / \mathrm{AgCl}$. The original curves were reported, without any smoothness. To exactly determine the maximum point of current transient curve, a polynomial curve was fitted to it around the peak. In addition, scanning electron microscopy (SEM) and x-ray diffraction (XRD) methods were used for morphological analysis and phase identification, respectively.

\section{Results and discussion:}

Fig. 1 shows the voltammograms measured at different scan rates; 5,30 and $150 \mathrm{mV} / \mathrm{s}$. The equilibrium reduction potential of $\mathrm{Ni}^{2+} / \mathrm{Ni}$ system was determined from crossing of reverse branch of voltammograms with potential axis, (where the current density is zero) and it was equal to $-0.4 \mathrm{~V}$ vs $\mathrm{Ag} / \mathrm{AgCl}$. According to this figure, the electrochemical deposition of $\mathrm{Ni}$ on FTO requires high overpotential about $0.4 \mathrm{~V}$, which implies the high energy barrier against nucleation. High overpotential required in electrochemical deposition of metals on semiconductor substrates has been reported in literature [5, 10, 11, 22, 24]. In anodic part of voltammograms, the anodic peak is clearly observed, however in cathodic part, the cathodic peak is not observed and the absolute value of cathodic current density increases continuously with increasing overpotential. The absence of cathodic peak in voltammograms, corresponding to electrochemical deposition of $\mathrm{Ni}$ on other semiconductor substrates, was reported in previous works $[14,22-25]$. One reason of this observation might be the side reduction of $\mathrm{H}^{+}$ions at high negative potentials [5, 14]. Anodic peak of Fig. 1 shows a shoulder which can be related to 
dissolution of hydrogen and of previously deposited Ni. Also, the main anodic peak is associated to oxidation of $\mathrm{Ni}[11]$.

Furthermore, by increasing the scan rate, the anodic peak maximum increases and its peak position shifts to more positive potentials. Also, the cathodic current density increases and its peak position shifts to more negative potentials with increasing the scan rate. This dependence of cathodic peak on the scan rate can be deduced from the slope of forward cathodic branch and the potential at which the falling portion of cathodic curve begins, although the cathodic peak can not be observed. These observations are characteristics of diffusion-limited electrochemical deposition process $[6,11,14,26]$. It predicts that the nucleation and subsequent growth of $\mathrm{Ni}$ on FTO, during electrochemical deposition, are controlled by diffusion of $\mathrm{Ni}^{2+}$ ions to the growing centers, which is prerequisite for the applicability of Scharifker-Hills model [8].

Chronoamperometry was used to obtain the current transient curves for the electrochemical deposition of Ni on FTO. The chronoamperometric measurement was carried out by stepping the potential from $-0.300 \mathrm{~V}$ vs $\mathrm{Ag} / \mathrm{AgCl}$ (as initialization step, where no $\mathrm{Ni}(\mathrm{II}$ ) reduction takes place) to different potentials between -0.750 and $-1.000 \mathrm{~V}$ vs $\mathrm{Ag} / \mathrm{AgCl}$. Depending on the applied potential, the chronoamperometric measurement time was different. It is sufficient to continue the chronoamperometry up to few times of $t_{\max }$, where $t_{\max }$ is the time at which the maximum current density is observed. Fig. 2 shows the current transient curves measured at different potentials. According to this figure, $t_{\max }$ decreases with increasing the potential. Therefore, the chronoamperometric measurement was terminated at lower time for higher applied potential. Before discussing the chronoamperometric results, it is useful to illustrate different parts of a current transient curve. Fig. 3 shows the current transient curve obtained at potential of $-0.800 \mathrm{~V}$ vs $\mathrm{Ag} / \mathrm{AgCl}$. As it is observed, a current transient curve consists 
of four segments. These segments are explained according to references $[8,27]$. In the first segment $\left(t_{1}\right)$ the potential of $-0.300 \mathrm{~V}$ vs $\mathrm{Ag} / \mathrm{AgCl}$ is applied, as initializing step. Because this potential is more positive than the equilibrium reduction potential of $\mathrm{Ni}^{2+}$ ions no nucleation can be occurred. After this segment, where the final potential is applied, an abrupt rise in current density is observed and it decays suddenly, which corresponds to double layer charging. The second segment $\left(t_{2}\right)$ is the induction period, which may be attributed to adsorption-desorption of $\mathrm{Ni}^{2+}$ ions. In this segment, adsorbed $\mathrm{Ni}$ atoms form unstable embryo, which under fluctuation may be detached from surface or may by grown to stable nuclei. In this period no significant nucleation can occur and thus no significant current density is observed. After some period of time, i.e. after induction period, the embryo growth dominates the embryo detachment, which leads to the appearance of significant number of nuclei. The third segment $\left(t_{3}\right)$, where nucleation occurs, reflects the rise in current density. This is due to the increase of electroactive surface area, either by isolated growth of all Ni nuclei or by increasing the number of nuclei. During this stage, the growth of nuclei takes place by hemispherical diffusion of electroactive species through diffusion zone, which has been developed around each nucleus. In fourth segment $\left(t_{4}\right)$, by further growing of individual nucleus the diffusion zones overlap and the hemispherical diffusion gives way to linear planar diffusion, which leads to the occurrence of maximum current density $\left(I_{\max }\right)$ at $t=t_{\max }$. After $t_{\max }$, the growth process is controlled by linear diffusion to planar surface of electrode. According to Fig. 2, all current transient curves exhibit the similar trend. However, by decreasing the potential (more negative potential) $t_{\max }$ decreases and $I_{\max }$ increases. The decrease of $t_{\max }$ is due to the higher overpotential, which decreases the activation energy against nucleation and facilitates the nucleation process. The increase of $I_{\max }$ is due to the higher nucleus density at higher overpotential, which leads to the larger electroactive area. Also, with 
increasing the applied potential, the second segment $\left(t_{2}\right)$ decreases, such that it disappears at high applied potentials. Again, this is due to the lower activation energy against nucleation, which facilitates the embryo growth into stable nucleus at shorter times against embryo detachment.

The above mentioned features are qualitatively consistent with the Scharifker-Hills physical model [8], which describes 3D nucleation and the subsequent diffusion-controlled growth. According to this model, the current transients corresponding to two extreme nucleation modes, i.e. instantaneous and progressive nucleation modes, can be described by the following equations [8];

for instantaneous nucleation;

$I(t)=\frac{z F D^{1 / 2} c}{\pi^{1 / 2} t^{1 / 2}}[1-\exp (-N \pi k D t)]$

and for progressive nucleation;

$I(t)=\frac{z F D^{1 / 2} c}{\pi^{1 / 2} t^{1 / 2}}\left[1-\exp \left(-A N_{\infty} \pi k^{\prime} D t^{2} / 2\right)\right]$

In above equations, $I(t)$ is the current density, $t$ is time, $z$ is the valency of electroactive metal ion, $F$ is Faraday's constant, $D$ is the diffusion coefficient, $c$ is the bulk concentration of electroactive metal ion, $k$ and $k^{\prime}$ are numerical constants determined by the conditions of the experiment, $A$ is steady state nucleation rate constant per site, $N_{\infty}$ is the number density of active sites and $N$ is the number density of instantaneously formed nuclei. One way of identifying the mechanism of nucleation is to compare the current transient data at early stage of electrochemical deposition (stage $t_{3}$ ) to that of instantaneous and progressive models. At short times, $N \pi k D t \ll 1$ and as a result $1-\exp (-N \pi k D t) \simeq N \pi k D t$. Thus, at early stage of electrochemical deposition equation 1 becomes [8];

$I(t)=z F D^{3 / 2} c \pi^{1 / 2} N k t^{1 / 2}$ 
and similarly, since $1-\exp \left(-A N_{\infty} \pi k^{\prime} D t^{2} / 2\right) \simeq A N_{\infty} \pi k^{\prime} D t^{2} / 2$, Equation 2 becomes;

$I(t)=1 / 2 z F D^{3 / 2} c \pi^{1 / 2} A N_{\infty} k^{\prime} t^{3 / 2}$

According to equations 3 and 4, the plot of $I$ vs $t^{1 / 2}$ for instantaneous nucleation and the plot of $I$ vs $t^{3 / 2}$ for progressive nucleation must be linear. For each current transient curve, $t$ in equations 3 and 4 was measured with respect to the beginning of $t_{3}$ stage. Thus $t_{1}$ and $t_{2}$ values were subtracted from electrochemical deposition time. Accordingly, $t_{3}$ segment of current transient curves were plotted in Fig. 4 as both $I$ vs $t^{1 / 2}$ and $I$ vs $t^{3 / 2}$ for different potentials. As it can be observed, for all potentials the plot of $I$ vs $t^{1 / 2}$ is linear, but that of $I$ vs $t^{3 / 2}$ deviates from linearity. This implies that the electrochemical deposition of Ni on FTO exhibits instantaneous nucleation. Furthermore, the nucleation mechanisms can be distinguished directly by rewriting equations 2 and 3 in terms of $I_{\max }$ and $t_{\max }$ [8]. For instantaneous nucleation it becomes;

$\frac{I^{2}}{I_{\max }^{2}}=\frac{1.9542}{t / t_{\max }}\left[1-\exp \left(-1.2564 t / t_{\max }\right)\right]^{2}$

and for progressive nucleation it becomes;

$\frac{I^{2}}{I_{\max }^{2}}=\frac{1.2254}{t / t_{\max }}\left[1-\exp \left(-2.3367\left(t / t_{\max }\right)^{2}\right)\right]^{2}$

The current transient curves in Fig. 2 were plotted in normalized form in Fig.5 together with theoretical curves for instantaneous and progressive nucleation according to equations 5 and 6 . A good agreement is observed between experimental and instantaneous curves, which it again implies that the electrochemical deposition of $\mathrm{Ni}$ on FTO is governed by 3D instantaneous nucleation.

A further expression can be derived, which relates $I_{\max }{ }^{2} t_{\max }$ with the diffusion coefficient of electroactive metal ion according to the following equation $[5,8]$ : 
for instantaneous nucleation the expression is;

$I_{\max }^{2} t_{\max }=0.1629(z F c)^{2} D$

and for progressive nucleation it is:

$I_{\max }^{2} t_{\max }=0.2598(z F C)^{2} D$

Since all the terms on the right hand side of equations 7 and 8 are independent of applied potential, the Scharifker-Hills model requires that $I_{\max }^{2} t_{\max }$ to be independent of applied potential. The values of $I_{\max }, t_{\max }$ and $I_{\max }^{2} t_{\max }$ were included in Table 1 for different potentials. Since the current transient curves are slightly noisy, to obtain the accurate values of $I_{\max }$ and $t_{\max }$, a polynomial curve was fitted to current transient curve around the maximum peak. Then, $I_{\max }$ and $t_{\max }$ were obtained from the fitted curve. As it can be observed, $I_{\max }^{2} t_{\max }$ is approximately independent of applied potential, which again confirms the applicability of the model used in this study. The mean value of diffusion coefficient of $\mathrm{Ni}^{2+}$ ion was estimated from the mean value of $I_{\max }^{2} t_{\max }\left(6787.9 \mathrm{~mA}^{2} \mathrm{~cm}^{-4} \mathrm{~s}\right)$ using equation 7 and it was obtained equal to $0.9 \times 10^{-6} \mathrm{~cm}^{2} \mathrm{~s}^{-1}$. For comparison, diffusion coefficients of different ions, which were determined from equations 7 and 8 , reported in literature, were included in Table 2, together with that obtained in the present work. As it can be observed the value of diffusion coefficient of $\mathrm{Ni}^{2+}$ ion in the present work has the same order of magnitude as those reported in literature. However, the observed differences are due to the differences in the type of ions, in the type of substrates, in the composition of electrochemical deposition bath and in the bath temperature.

In addition, SEM image was used to verify that the nucleation mechanism during electrochemical deposition of Ni on FTO is instantaneous. To obtain this image, electrochemical deposition was done under chronoamperometry condition at $-0.8 \mathrm{~V}$ (vs $\mathrm{Ag} / \mathrm{AgCl}$ ) for $15 \mathrm{~s}$ (see Fig. 6). As it can be observed, the size of nuclei is uniform. This is an evidence of instantaneous 
nucleation mechanism during electrochemical deposition of Ni on FTO._Also, XRD pattern of electrochemically deposited $\mathrm{Ni}$ on FTO at $-0.880 \mathrm{~V}$ (vs $\mathrm{Ag} / \mathrm{AgCl}$ ) was measured and it was given in Fig. 7. In this pattern, diffraction peaks corresponding to $\mathrm{SnO}_{2}$ and Ni peaks are observed. $\mathrm{SnO}_{2}$ peaks are due to the diffraction of x-ray by FTO substrate. According to this pattern, the electrochemically deposited $\mathrm{Ni}$ is single phase and fully crystalline. The halo in background of pattern is due to the amorphous underlying glass of FTO.

Side reduction of $\mathrm{H}^{+}$ions at high negative potential is an issue in electrochemical deposition of $\mathrm{Ni}$, especially on semiconductor substrates due to its higher overpotential. It was stated that $\mathrm{H}^{+}$reduction supplies cathodic current in addition to that of the $\mathrm{Ni}^{2+}$ ion reduction [14]. Hydrogen evolution is significantly affected by $\mathrm{pH}$ of electrochemical deposition bath, which is highest at low $\mathrm{pH}$. Watt's bath is a suitable choice from this point of view. Also, it was stated that in the case of electrochemical deposition of $\mathrm{Ni}$ on $\mathrm{n}$-Si substrate, size of nuclei decreases with reduction of $\mathrm{pH}$ which leads to fine grain Ni coating [14]. For metallization applications, the fine grain of metallized coating is not suitable, since fine grain structure reduces the conductivity of coating. On the other hand, at $\mathrm{pH}$ values above 5 the internal stress increase, which leads to cracking of coating. Therefore, boric acid is added to Watt's bath as a $\mathrm{pH}$ buffer. It was stated that in Watt's bath $\mathrm{Ni}\left(\mathrm{H}_{2} \mathrm{BO}_{3}\right)_{2}$ complex is formed between $\mathrm{Ni}^{2+}$ and $\mathrm{H}_{3} \mathrm{BO}_{3}$ in $\mathrm{pH}$ range of 4-5.5 [30, 31]. The general mechanism of the electrochemical deposition of $\mathrm{Ni}$ from Watt's bath is according to the following reactions [14, 32]:

$N i^{2+}+X^{-} \leftrightarrow N i X^{+}$

$N i X^{+}+e^{-} \leftrightarrow N i X_{a d s}$

$N i X_{a d s .}+e^{-} \leftrightarrow N i+X^{-}$

Where, $X$ has been assumed to be $\mathrm{OH}^{\top}$ or $\mathrm{Cl}^{\top}$ and subscript $a d s$. denotes the adsorbed species. 


\section{Conclusion:}

In this work, mechanism of nucleation and growth of Ni on FTO substrate during electrochemical deposition was investigated. Voltammetric measurement showed that high overpotential is required for electrochemical deposition of Ni on FTO, which is due to the large energy barrier against nucleation. Also, from the scan rate dependence of cathodic and anodic peaks, it was revealed that the nucleation and growth are controlled by diffusion of $\mathrm{Ni}^{2+}$ ions to growing centers. The mechanism of nucleation and growth was determined from current transient curves. By comparing these curves to those calculated from Scharifker-Hills model, it was found that the electrochemical deposition of Ni on FTO is governed by instantaneous nucleation mechanism. In addition, diffusion coefficient of $\mathrm{Ni}^{2+}$ was determined from transient curves and it was equal to $0.9 \times 10^{-6} \mathrm{~cm}^{2} \mathrm{~s}^{-1}$. The obtained value has the same order of magnitude as those reported in literature for electrochemical deposition of other ions on other semiconductor substrates.

\section{Acknowledgement:}

This research was financially supported by Iran National Science Foundation (INSF) and by Shiraz University of Technology. The authors are grateful for these supports. 


\section{References:}

[1] J. S.Chan, T.C. Fu, N. W.Cheung, N. Newman, X. Liu, J. R. Ross, M. D. Rubin, P. Chu, Metallization of GaN thin films prepared by ion beam assisted molecular beam epitaxy, MRS Proceedings 339 (1994) 223-228.

[2] T. Uusluoto, P. Jalonen, H. Laaksonen, A. Tuominen, Metallization of microvias by sputterdeposition, Microelectron. Reliab. 44 (2004) 587-593.

[3] M. Datta, D. Landolt, Fundamental aspects and applications of electrochemical microfabrication, Electrochim. Acta 45 (2000) 2535-2558.

[4] A. Sahari, A. Azizi, N. Fenineche, G. Schmerber, A. Dinia, Nucleation and surface morphology of cobalt films electrodeposited on Pt/Si substrates, Surf. Rev. Lett. 12 (2005) 391396.

[5] G. Oskam, J. G. Long, A. Natarajan, P. C. Searson, Electrochemical deposition of metals onto silicon, J. Phys. D: Appl. Phys. 31(1998) 1927-1949.

[6] M. R. Khelladi, L. Mentar, A. Azizi, A. Sahari, A. Kahoul, Electrochemical nucleation and growth of copper deposition onto FTO and n-Si(100) electrodes, Mater. Chem. Phys. 115 (2009) 385-390.

[7] I. Villareal, E. Morales, J. L. Acosta, Nucleation and growth of $\mathrm{LiCF}_{3} \mathrm{SO}_{3}$-doped polyalkylthiophenes, Polymer 42 (2001) 3779-3789.

[8] B. Scharifker, G. Hills, Theoretical and experimental studies of multiple nucleation, Electrochim. Acta 28 (1983) 879-889. 
[9] C. Scheck, P. Evans, G. Zangari, R. Schad, Sharp ferromagnet/semiconductor interfaces by electrodeposition of Ni thin films onto n-GaAs (001) substrates, Appl. Phys. Lett. 82 (2003)2853-2855.

[10] L.O.S Bulhões, L.H. Mascaro, Electrochemical nucleation of lead and copper on indium-tin oxide electrodes, J. Solid State Electrochem. 8 (2004) 238-243.

[11] M.R. Khelladi, L. Mentar, M. Boubatra, A. Azizi, A. Kahoul, Early stages of cobalt electrodeposition on FTO and n-type Si substrates in sulfate medium, Mater. Chem. Phys. 122 (2010) 449-453.

[12] L. Mentar, Early stages of cobalt-copper alloys electrodeposition onto fluorine-doped tin oxide electrodes in sulfate solution, Oriental J. Chem. 27 (2011) 477-483.

[13] K.R. Saravanan, S. Sathyamoorthi, D. Velayutham , V. Suryanarayanan, Electrodeposition of nickel on boron-doped diamond from an air-stable methyl sulphate anion based ionic liquid, Electrochim. Acta 98 (2013) 88-93.

[14] F. Nasirpouri, S. M. Janjan, S. M. Peighambari, M. G. Hosseini, A. Akbari, A. S. Samardak, Refinement of electrodeposition mechanism for fabrication of thin nickel films on n-type silicon (111), J. Electroanal Chem. 690 (2013) 136-143.

[15] A. R. Burgers, How to design optimal metallization patterns for solar cells. Prog. Photovoltaics: Res. Appl. 7 (1999) 457-461.

[16] L. Wen, L. Yueqiang, C. Jianjun, C. Yanling, W. Xiaodong, Y. Fuhua, Optimization of grid design for solar cells, J. Semicond. 31 (2010) 014006(1-4). 
[17] J. Geissbühler, S. D. Wolf, A. Faes, N. Badel, Q. Jeangros, A. Tomasi, L. Barraud, A. Descoeudres, M. Despeisse, C. Ballif, Silicon heterojunction solar cells with copper-plated grid electrodes: status and comparison with silver thick-film techniques, IEEE J. Photovoltaics 4 (2014) 1055-1062.

[18] M. Späth, P.M. Sommeling, J.A.M. van Roosmalen, H.J.P. Smit, N.P.G. van der Burg, D.R. Mahieu, N.J. Bakker, J.M. Kroon, Reproducible manufacturing of dye-sensitized solar cells on a semi-automated baseline, Prog. Photovoltaics: Res. Appl. 11 (2003) 207-220.

[19] K. Okada, H. Matsui, T. Kawashima, T. Ezure, N. Tanabe, $100 \mathrm{~mm} \times 100 \mathrm{~mm}$ large-sized dye sensitized solar cells, J. Photoch. Photobio. A: Chem. 164 (2004) 193-198.

[20] R. Sastrawan, J. Beier, U.Belledin, S. Hemming, A. Hinsch, R. Kern, C. Vetter, F.M. Petrat, A. Prodi-Schwab, P. Lechner, W. Hoffmann, A glass frit-sealed dye solar cell module with integrated series connections, Sol. Energ. Mat. Sol. Cells 90 (2006) 1680-1691.

[21] S.H. Seo, H.J. Kim, B.K. Koo, D.Y. Lee, Effects of non-noble metal current-collecting grids on internal resistance for dye-sensitized solar cells, J. Electrochem. Soc. 156 (2009) F128-F130.

[22] H.P. Feng, T. Paudel, B. Yu, S. Chen, Z.F. Ren, G. Chen, Nanoparticle-enabled selective electrodeposition, Adv. Mater. 23 (2011) 2454-2459.

[23] A. Slabon, F. Krumeich, F. Wächter, R. Nesper, Fabrication of nanoporous nickel coatings by template-assisted electrodeposition, Chem. Electro. Chem. Commun. 1 (2014) 536-538. 
[24] H.J. Su, M.Y. Zhang, Y.H. Chang, P. Zhai, N.Y. Hau, Y.T Huang, C. Liu, A.K. SohK, S.P. Feng, Highly conductive and low cost Ni-PET flexible substrate for efficient dye-sensitized solar cells, ACS Appl. Mater. Interf. 6 (2014) 5577-5584.

[25] M. Torabi, R. Khalifehzadeh, H. Arami, S. K. Sadrnezhaad, Electrochemical deposition of flower-like nickel nanostructures on well-defined n-Si(111), IJE Transactions B: Appl 21 (2008) $177-182$.

[26] K. Anuar, W.T. Tan, M.S. Atan, K. Dzulkefly, S.M. Ho, H.M. Jelas, N. Saravanan, Cyclic voltammetry study of copper tin sulfide compounds, Pacific. J. Sci. Technol. 8 (2007) 252-260.

[27] H. Bort, K. Jütiner, W.J. Lorenz, G. Staikov, E. Budevski, Underpotential-overpotential transition phenomena in metal deposition processes, Electrochim. Acta 28 (1983) 985-991.

[28] R. Krumm, B. Guel, C. Schmitz, G. Staikov, Nucleation and growth in electrodeposition of metals on n-Si(111), Electrochim. Acta 45 (2000) 3255-3262.

[29] A. Sahari, A. Azizi, G. Schmerber, A. Dinia, Nucleation, growth, and morphological properties of electrodeposited nickel films from different baths, Surf. Rev. Lett. 15 (2008) 717725.

[30] K.-M. Yin, B.-T. Lin, Effects of boric acid on the electrodeposition of iron, nickel and ironnickel, Surf. Coat. Technnol. 78 (1996) 205-210.

[31] B. V. Tilak, A. S. Gendront, M. A. Mosoiu, Borate buffer equilibria in nickel refining electrolytes, J. Appl. Electrochem. 7 (1977) 495-500.

[32] A. Saraby-Reintjes and M. Fleischmann, Kinetics of Electrodeposition of nickel from Watts baths, Electrochim. Acta 29 (1984) 557-566. 


\section{Figure captions:}

Fig. 1 Voltammograms for electrochemical deposition of Ni on FTO at different scan rates; 5,30 and $150 \mathrm{mV} / \mathrm{s}$

Fig. 2 Current transient curves for electrochemical deposition of Ni on FTO at different potentials

Fig. 3 Current transient curve for electrochemical deposition of Ni on FTO at potential of $-0.800 \mathrm{~V}$ vs $\mathrm{Ag} / \mathrm{AgCl}$. This curve shows different segments of a current transient curve Fig. 4 Plot of early stage of current transient curves for electrochemical deposition of $\mathrm{Ni}$ on FTO; (a) in $I$ vs $t^{1 / 2}$ and (b) in $I$ vs $t^{3 / 2} . R^{2}$ is R-squared value, which shows the quality of curve fitting to experimental data

Fig. 5 Normalized plot of measured current transient curves for electrochemical deposition of Ni on FTO, together with those calculated from Scharifker-Hills model for both instantaneous and progressive nucleation mechanisms

Fig. 6 SEM image of Ni islands on FTO. Electrochemical deposition was done at $-0.8 \mathrm{~V}$ (vs $\mathrm{Ag} / \mathrm{AgCl})$ for $15 \mathrm{~s}$

Fig. 7 XRD pattern of electrochemically deposited $\mathrm{Ni}$ on FTO at $-0.880 \mathrm{~V}$ (vs $\mathrm{Ag} / \mathrm{AgCl})$. Phase identification was done by comparing the XRD pattern to reference JCPDS files. 


\section{Table captions:}

Table 1 The values of $t_{\max }, I_{\max }$ and $I_{\max }^{2} t_{\max }$ for different potentials. These parameters were determined from current transient curves for electrochemical deposition of $\mathrm{Ni}$ on FTO

Table 2 The diffusion coefficient of $\mathrm{Ni}^{2+}$ ion determined in the present work together with that reported in literature for different ions during electrochemical deposition on different semiconductor substrates 


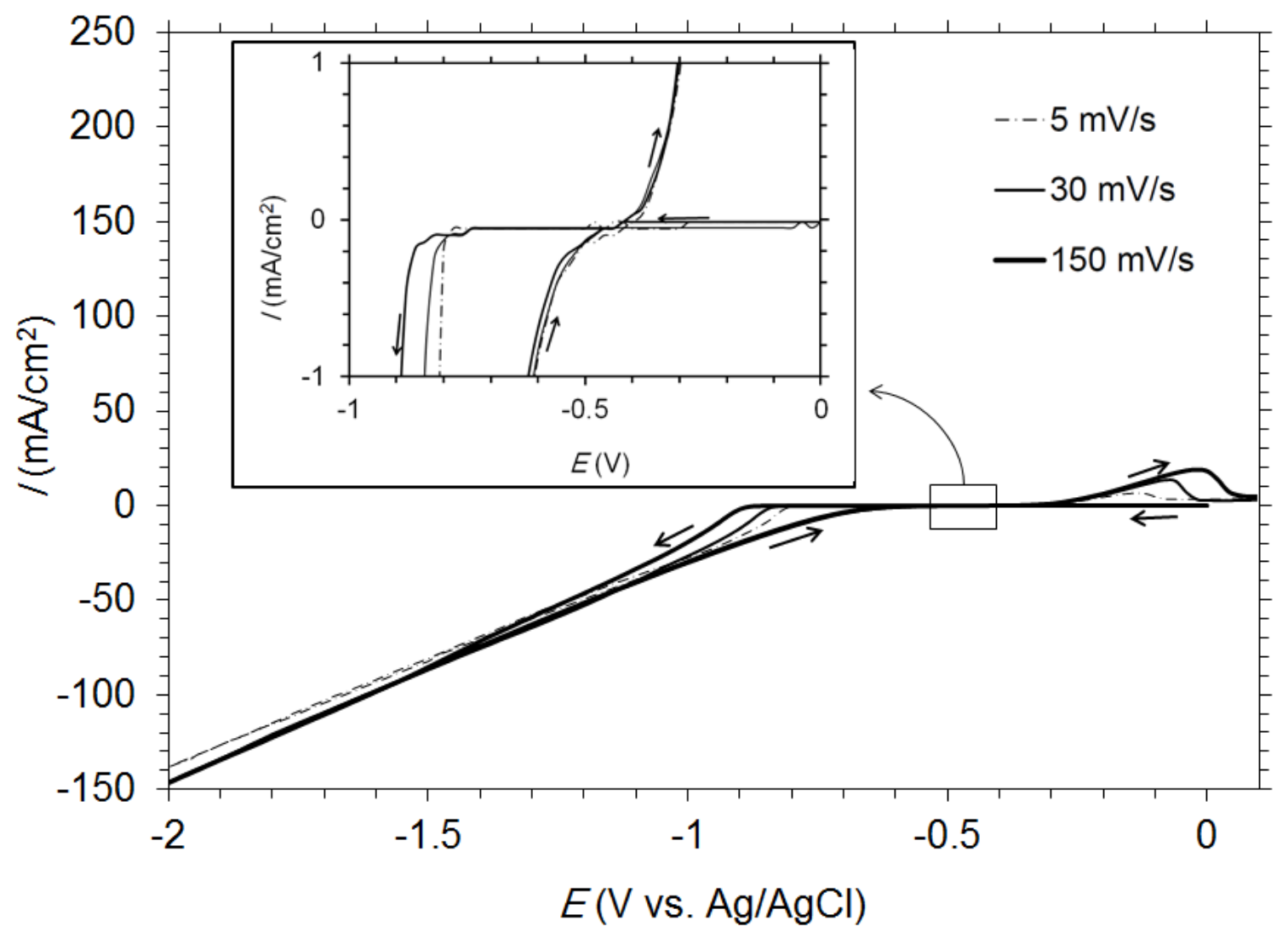


Figure 2

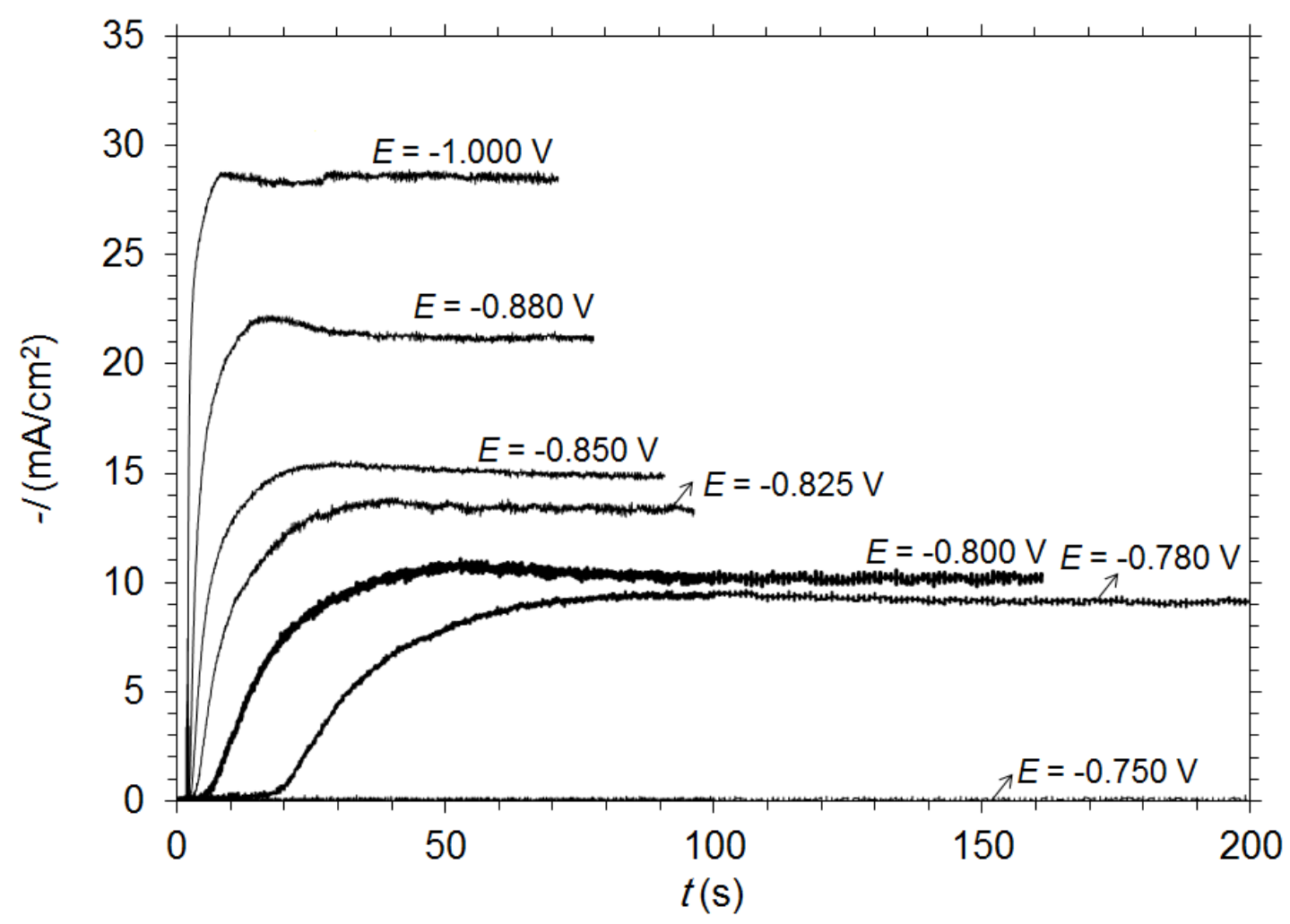


Figure 3

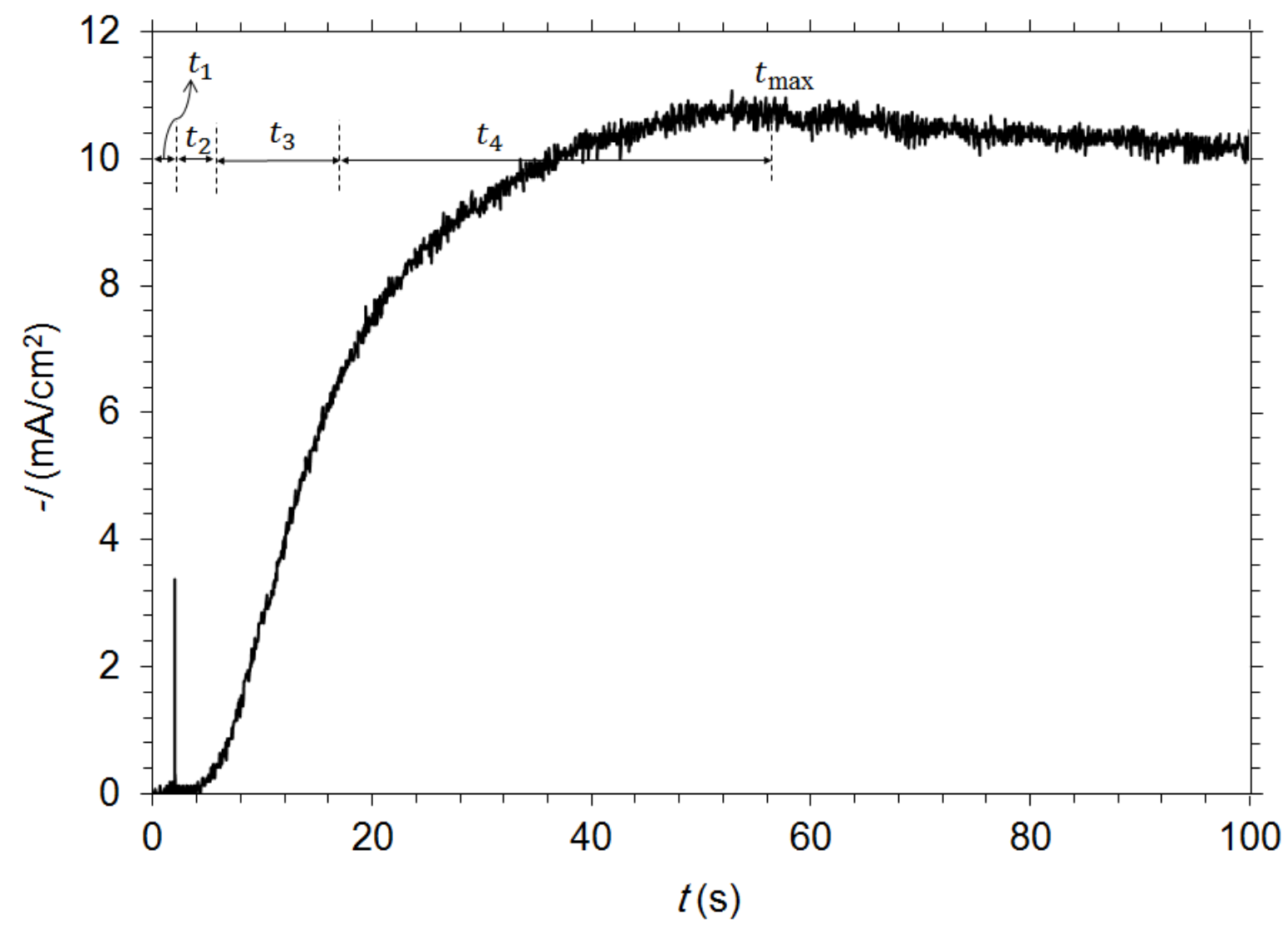




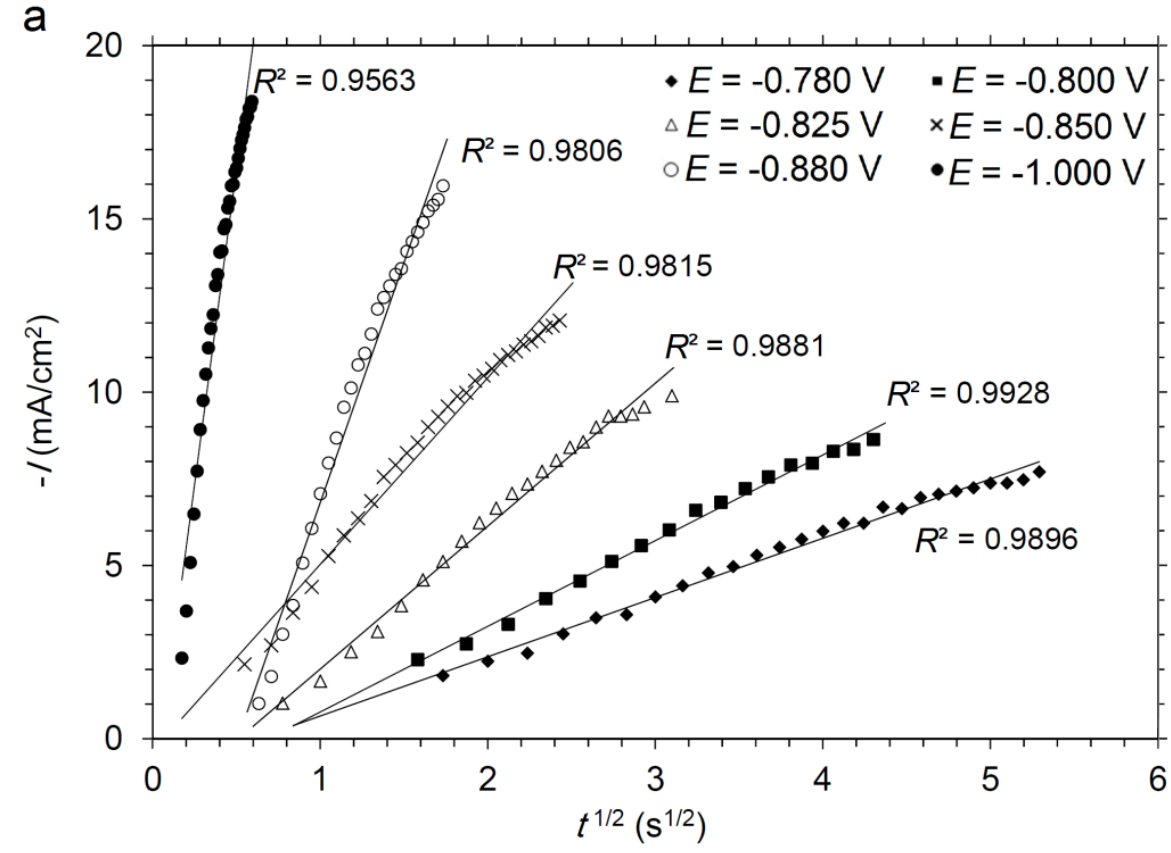

b

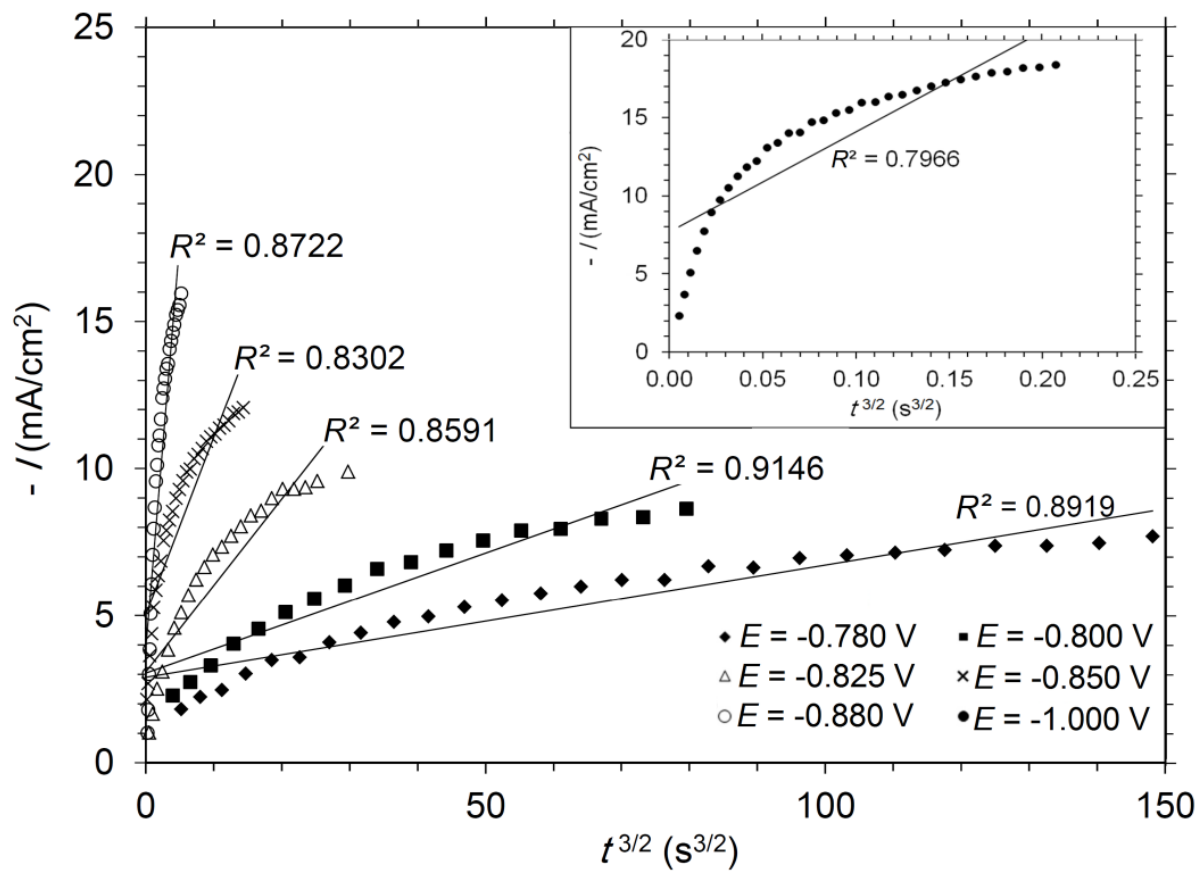


Figure 5 (1,
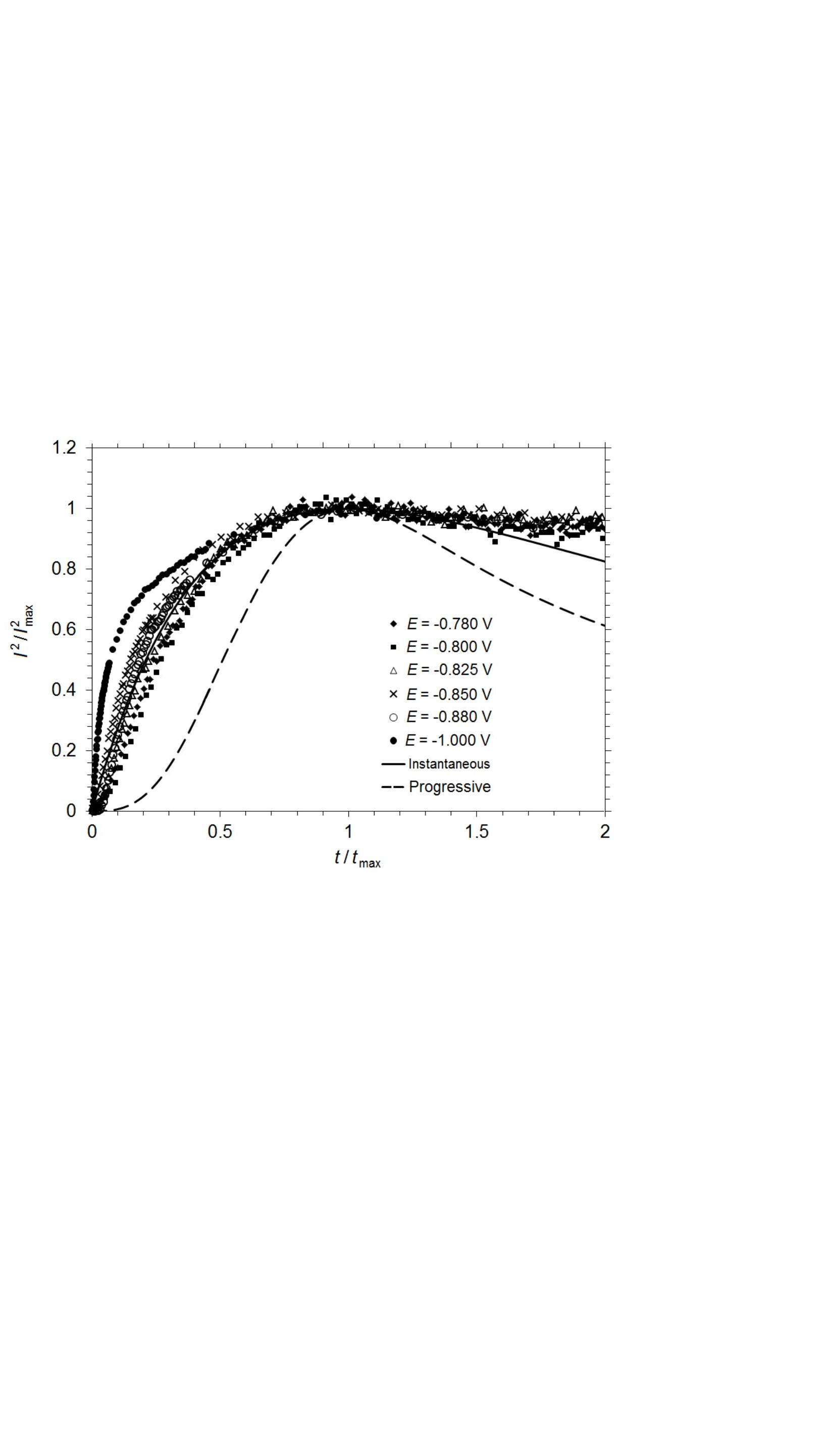


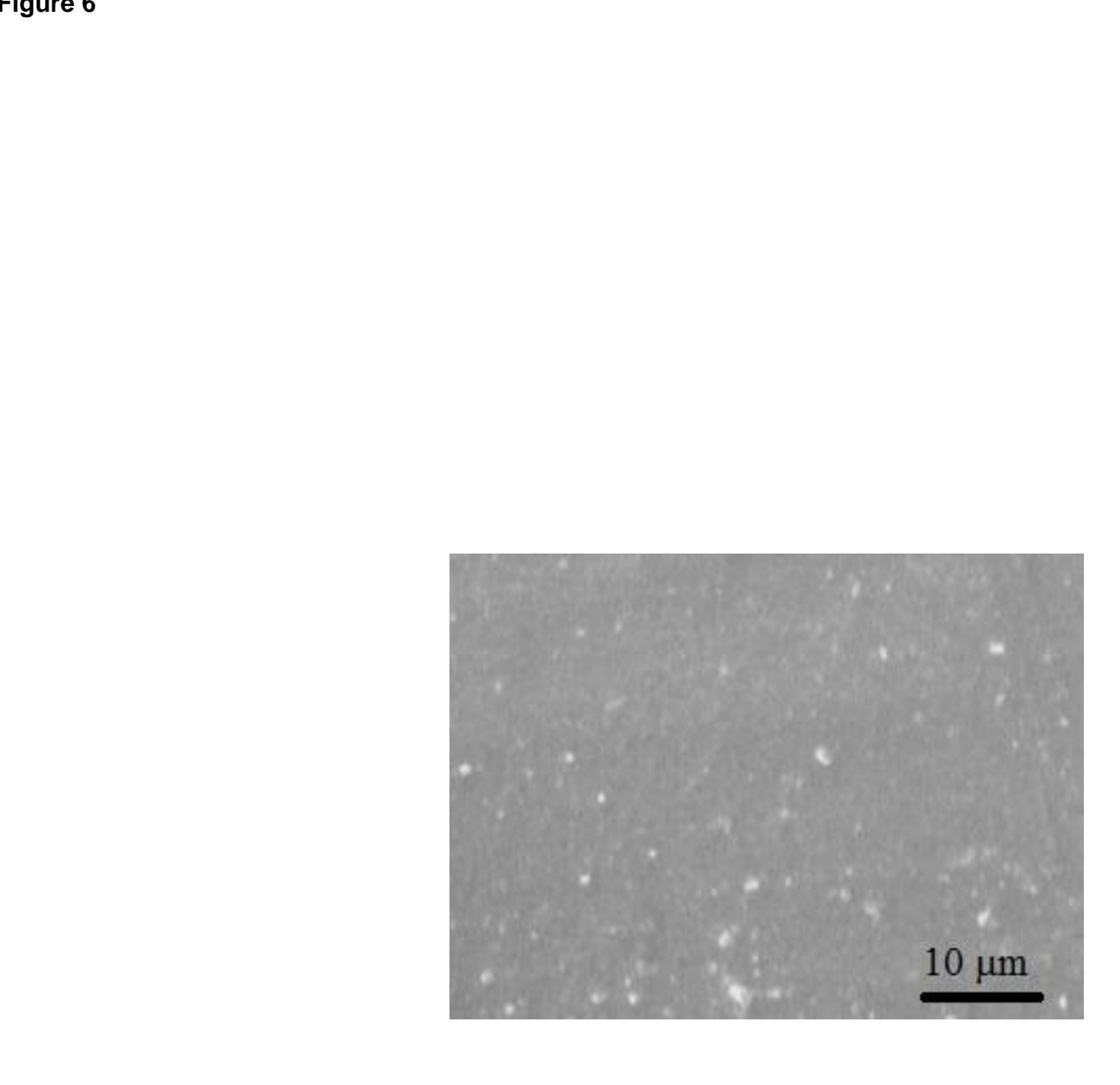

Figure 6

$10 \mu \mathrm{m}$
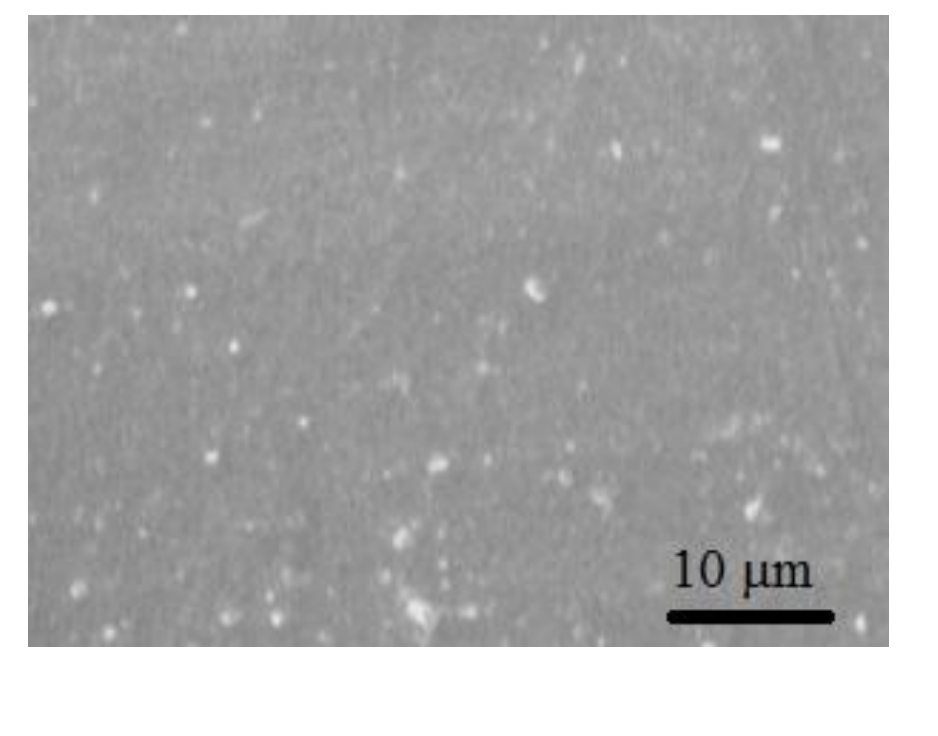

.

( .
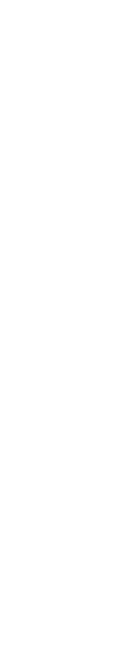


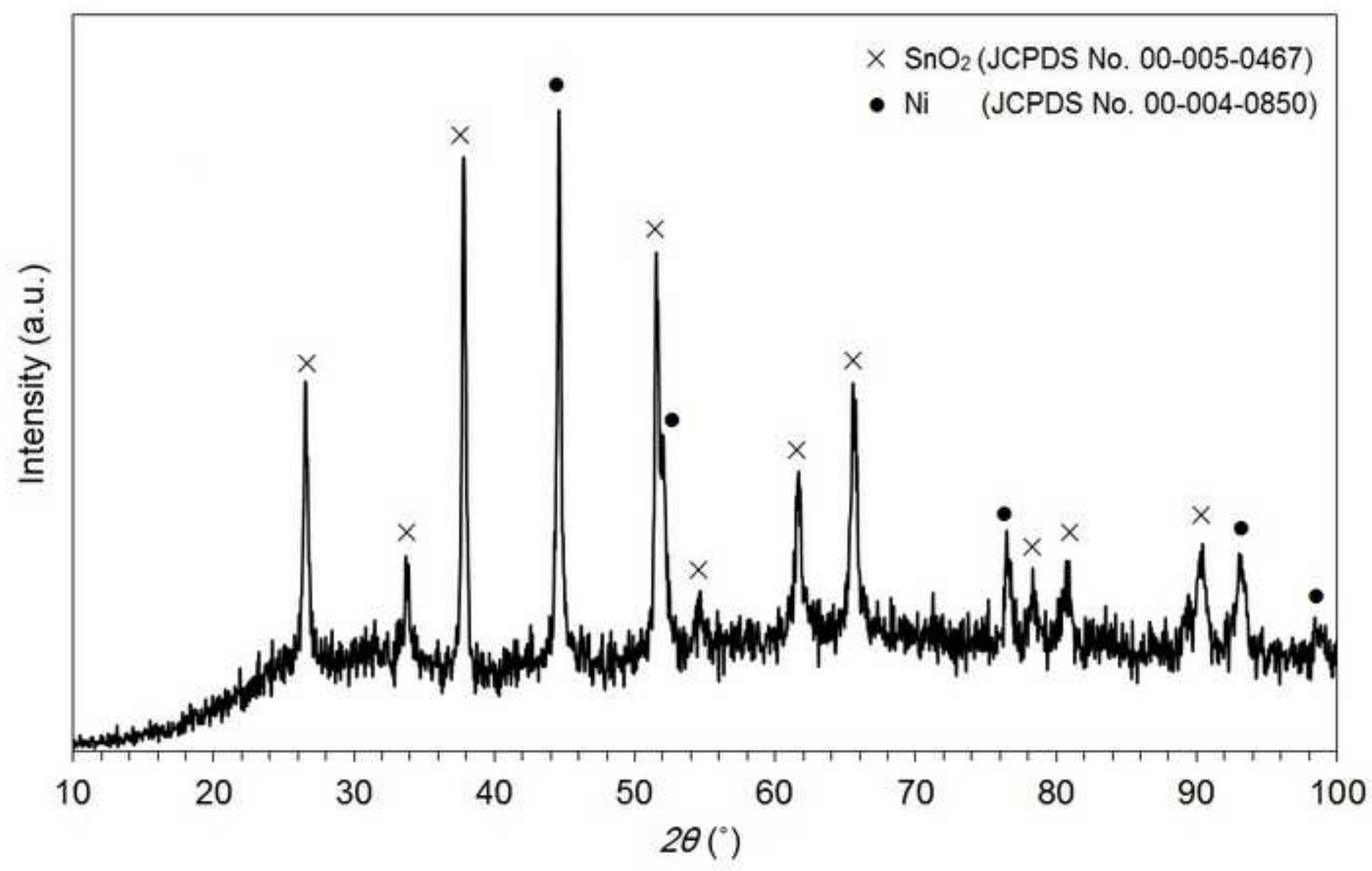


Table 1

\begin{tabular}{cccc}
\hline$E(\mathrm{~V}$ vs. $\mathrm{Ag} / \mathrm{AgCl})$ & $t_{\max }(\mathrm{s})$ & $I_{\max }\left(\mathrm{mA} \mathrm{cm}^{-2}\right)$ & $I_{\max }^{2} t_{\max }\left(\mathrm{mA}^{2} \mathrm{~cm}^{-4} \mathrm{~s}\right)$ \\
\hline-0.780 & 79.0 & 9.4 & 7010.2 \\
-0.800 & 50.0 & 11.0 & 6050.0 \\
-0.825 & 39.0 & 13.6 & 7213.4 \\
-0.850 & 27.9 & 15.4 & 6616.8 \\
-0.880 & 15.2 & 22.0 & 7356.8 \\
-1.000 & 7.2 & 30.0 & 6480.0 \\
\hline
\end{tabular}




\begin{tabular}{|c|c|c|c|c|c|}
\hline Ion type & Substrate type & $\begin{array}{l}\text { Bath temperature } \\
\left({ }^{\circ} \mathrm{C}\right)\end{array}$ & Bath composition & $D\left(\mathrm{~cm}^{2} \mathrm{~s}^{-1}\right)$ & Reference \\
\hline $\mathrm{Ni}^{2+}$ & FTO & 45 & $\begin{array}{l}\text { Aqueous solution of } 256 \mathrm{~g} / \mathrm{L} \mathrm{NiSO}{ }_{4}{ }^{*} 6 \mathrm{H}_{2} \mathrm{O} \\
32 \mathrm{~g} / \mathrm{L} \mathrm{NiCl}_{2} \cdot 6 \mathrm{H}_{2} \mathrm{O}, 40 \mathrm{~g} / \mathrm{L} \mathrm{H}_{3} \mathrm{BO}_{3}\end{array}$ & $0.9 \times 10^{-6}$ & Present work \\
\hline $\mathrm{Co}^{2+}$ & FTO & 25 & $\begin{array}{l}\text { Aqueous solution of } 0.25 \mathrm{M} \mathrm{CoSO}_{4} \cdot 7 \mathrm{H}_{2} \mathrm{O} \\
\qquad 1 \mathrm{M} \mathrm{Na}_{2} \mathrm{SO}_{4}, 0.5 \mathrm{M} \mathrm{H}_{3} \mathrm{BO}_{3}\end{array}$ & $1.1 \times 10^{-5}$ & [11] \\
\hline $\mathrm{Co}^{2+}$ & $\mathrm{n}-\mathrm{Si}(100)^{*}$ & 25 & $\begin{array}{l}\text { Aqueous solution of } 0.25 \mathrm{M} \mathrm{CoSO}_{4} \cdot 7 \mathrm{H}_{2} \mathrm{O} \\
\qquad 1 \mathrm{M} \mathrm{Na}_{2} \mathrm{SO}_{4}, 0.5 \mathrm{M} \mathrm{H}_{3} \mathrm{BO}_{3}\end{array}$ & $1.0 \times 10^{-5}$ & [11] \\
\hline $\mathrm{Pb}^{2+}$ & $\mathrm{ZnO}$ single crystal & - & $\begin{array}{l}\text { Aqueous solution of } 0.05 \mathrm{M} \mathrm{Pb}\left(\mathrm{NO}_{3}\right)_{2}, 1 \mathrm{M} \\
\mathrm{KNO}_{3}\end{array}$ & $0.42 \times 10^{-5}$ & [8] \\
\hline $\mathrm{Cu}^{2+}$ & FTO & $20-25$ & $\begin{array}{l}\text { Aqueous solution of } 0.005 \mathrm{M} \mathrm{CuSO}_{4}, 1 \mathrm{M} \\
\qquad \mathrm{Na}_{2} \mathrm{SO}_{4}, 0.5 \mathrm{M} \mathrm{H}_{3} \mathrm{BO}_{3}\end{array}$ & $5.76 \times 10^{-5}$ & {$[6]$} \\
\hline $\mathrm{Cu}^{2+}$ & $\mathrm{n}-\mathrm{Si}(100)$ & $20-25$ & $\begin{array}{l}\text { Aqueous solution of } 0.005 \mathrm{M} \mathrm{CuSO}_{4}, 1 \mathrm{M} \\
\qquad \mathrm{Na}_{2} \mathrm{SO}_{4}, 0.5 \mathrm{M} \mathrm{H}_{3} \mathrm{BO}_{3}\end{array}$ & $8.96 \times 10^{-6}$ & [6] \\
\hline $\mathrm{Pb}^{2+}$ & $\mathrm{ITO}^{\mathrm{f}}$ & - & $\begin{array}{l}\text { Aqueous solution of } 0.02 \mathrm{M} \mathrm{Pb}\left(\mathrm{NO}_{3}\right)_{2}, 1 \mathrm{M} \\
\qquad \mathrm{NaNO}_{3}\end{array}$ & $4.6 \times 10^{-6}$ & [10] \\
\hline $\mathrm{Cu}^{2+}$ & ITO & - & $\begin{array}{l}\text { Aqueous solution of } 0.1 \times 10^{-4} \mathrm{M} \mathrm{Cu}\left(\mathrm{NO}_{3}\right)_{2} \\
\qquad 1 \mathrm{M} \mathrm{NaNO}_{3}\end{array}$ & $2.04 \times 10^{-6}$ & {$[10]$} \\
\hline $\mathrm{Tl}^{+}$ & $\mathrm{n}-\mathrm{Si}(111)^{\ddagger}$ & 25 & $\begin{array}{l}\text { Aqueous solution of } 0.005 \mathrm{M} \mathrm{Tl}_{2} \mathrm{SO}_{4}, 0.5 \mathrm{M} \\
\qquad \mathrm{Na}_{2} \mathrm{SO}_{4}, 0.005 \mathrm{M} \mathrm{H}_{2} \mathrm{SO}_{4}\end{array}$ & $1.4 \times 10^{-5}$ & [28] \\
\hline $\mathrm{Cd}^{2+}$ & $\mathrm{n}-\mathrm{Si}(111)$ & 25 & $\begin{array}{l}\text { Aqueous solution of } 0.005 \mathrm{M} \mathrm{CdSO}_{4}, 0.5 \mathrm{M} \\
\qquad \mathrm{Na}_{2} \mathrm{SO}_{4}, 0.005 \mathrm{M} \mathrm{H}_{2} \mathrm{SO}_{4}\end{array}$ & $9.5 \times 10^{-6}$ & [28] \\
\hline $\mathrm{Ni}^{2+}$ (Sulfate bath) & $\mathrm{Pt} / \mathrm{Si}(100)^{\#}$ & Room temperature & $\begin{array}{l}\text { Aqueous solution of } 0.1 \mathrm{M} \mathrm{Ni}_{2} \mathrm{SO}_{4} \cdot 6 \mathrm{H}_{2} \mathrm{O}, 1 \\
\qquad \mathrm{M} \mathrm{Na}_{2} \mathrm{SO}_{4}, 0.5 \mathrm{M} \mathrm{H}_{3} \mathrm{BO}_{3}\end{array}$ & $2.5 \times 10^{-6}$ & [29] \\
\hline $\mathrm{Ni}^{2+}$ (watts bath) & $\mathrm{Pt} / \mathrm{Si}(100)$ & Room temperature & $\begin{array}{l}\text { Aqueous solution of } 0.01 \mathrm{M} \mathrm{NiCl}_{2} \cdot 6 \mathrm{H}_{2} \mathrm{O} \\
0.1 \mathrm{M} \mathrm{Ni}_{2} \mathrm{SO}_{4} 6 \mathrm{H}_{2} \mathrm{O}, 1 \mathrm{M} \mathrm{Na}_{2} \mathrm{SO}_{4}, 0.01 \mathrm{M}\end{array}$ & $2.14 \times 10^{-6}$ & [29] \\
\hline $\mathrm{Ni}^{2+}$ (Chloride bath) & $\mathrm{Pt} / \mathrm{Si}(100)$ & Room temperature & $\begin{array}{c}\mathrm{NaCl}, 0.5 \mathrm{M} \mathrm{H}_{3} \mathrm{BO}_{3} \\
\text { Aqueous solution of } 0.1 \mathrm{M} \mathrm{NiCl}_{2} \cdot 6 \mathrm{H}_{2} \mathrm{O}, 1 \\
\mathrm{M} \mathrm{NaCl}, 0.5 \mathrm{M} \mathrm{H}_{3} \mathrm{BO}_{3}\end{array}$ & $1.75 \times 10^{-6}$ & [29] \\
\hline \multicolumn{6}{|c|}{ * n-type silicon single crystal with (100) crystallographic plane. } \\
\hline \multicolumn{6}{|c|}{ f Tin doped-indium oxide } \\
\hline \multicolumn{6}{|c|}{ ‡ n-type silicon single crystal with (111) crystallographic plane. } \\
\hline \# Pt sputtered Si sing & al with (100) & lographic plane. & & & \\
\hline
\end{tabular}

